\title{
CT-supported analysis of the destructive effects of Varroa destructor on the pre-imaginal development of honey bee, Apis mellifera
}

\author{
Sándor KeszThelyi ${ }^{1}$, Tamás SIPOs $^{1}$, Ádám CsóKA ${ }^{2}$, Tamás DonKó ${ }^{2}$ \\ ${ }^{1}$ Department of Plant Production and Protection, Kaposvár University, S. Guba str. 40, Kaposvar H-7400, Hungary \\ ${ }^{2}$ Medicopus Nonprofit Ltd., S. Guba str 40, Kaposvar H-7400, Hungary
}

Received 22 October 2019 - Revised 26 July 2020 - Accepted 19 August 2020

\begin{abstract}
The ectoparasitic mite, Varroa destructor, is a most important health risk for European honey bee subspecies (Apis mellifera) globally. There is a scarcity in experimental approaches addressing this issue by using computed tomography. Our purpose was to determine the decrease in the volume, surface, density and weight alteration triggered by $V$. destructor in pre-imaginal stages of $A$. mellifera using computer-based 3-D reconstruction technology. Computer tomography used in the current study proved to be sufficiently sensitive for the detection of $V$. destructor in comb cells. This non-invasive experimental setup revealed that the developing worker pupae have retained their volume and surface values, whereas the weight loss triggered by $V$. destructor was statistically confirmed. In addition, the disappearance of lower radiodensity tissues is shown to be due to mite parasitism, which can be primarily explained by haemolymph losses.
\end{abstract}

computer tomography / pre-imaginal development / honey bee / impairment / Varroa destructor

\section{INTRODUCTION}

The honey bee mite Varroa destructor (Acari: Varroidae) is one of the most destructive natural enemy of the western honey bee, Apis mellifera (Anderson and Trueman 2000). Its original host is the eastern honey bee, Apis cerana; however, it attacks only its drone broods. It became a parasite for Apis mellifera subsequently, in areas in which both bee species coexist. Other host of this parasite mite is not known (Rosenkranz et al. 2010). It is native in Southeastern Asia, from where it started spreading worldwide. It has been present in Holarctic, Neotropical and

Corresponding author: S. Keszthelyi, ostrinia@gmail.com

Manuscript editor: Yves Le Conte
Indo-Australian regions for over 40 years (Sammataro et al. 2000).

There are several biological consequences in honey bee caused by $V$. destructor. Colony losses caused by $V$. destructor in the western honey bee are mainly due to worker bee injury caused by this parasite mite during pre-imaginal development (Duay et al. 2003). The most plausible side effect is the weight loss during the post-embryonic infestation. Body weight loss right after the onset of adult stage can reach $10 \%$ in infested populations (De Jong et al. 1982). The parasitised adult bee emerges injured with a reduced life expectancy and impaired orientation ability (De Jong and De Jong 1983).

Previous research results have been reported as to $V$. destructor being a typically haemolymph parasite of immature and adult honey bees (Shaw and Stobbart 1963). The latest results (Ramsey et al. 2019), however, 
showed that the parasite adheres to the body of the bee and weakens it by sucking its fat. It is a vector for at least 5 debilitating bee viruses including RNA viruses such as the virus inducing deformed wing development (Genersch and Aubert 2010; Anguiano-Baez et al. 2016). Through weakening the immune system, it facilitates the occurrence of other pathogens, which can cause the overall extinction of the infested bee family (Yang and Cox-Foster 2005).

Although a detailed, non-invasive study from Facchini et al.'s (2019) experiment on $V$. destructor infecting honey bees at different developmental stages has recently been published, experimental studies performed on honey bee hives mainly omitted the use of computed tomography hitherto, even though computed tomography offers a noninvasive approach.

The goal of this study was to analyse the effect brought about by $V$. destructor on the pre-imaginal stage of A. mellifera in a noninvasive manner. Our purpose was to assess the putative change in the volume, density and weight in post-embryonic stages of A. mellifera caused by this important mite parasite using computer-based three-dimensional reconstruction technology.

\section{MATERIAL AND METHODS}

\subsection{Sampling}

A "warm way"-built hive (with the frames perpendicular to the entrance) was placed next to Kaposi Somogy County Teaching Hospital, Dr. Baka Jozsef Diagnostic, Radiation Oncology, Research and Teaching Centre (GPS coordinates: WGS: X:46.381079 Y:17,826915), in which computer tomography (CT) was conducted at the commencement of August 2019. One colony of Apis mellifera carnica kept on 10 frames was the subject of our investigation. Copious honey and pollen were available to feed the colony, and in addition bees were fed with 50\% sugar drops during the survey. The young honey bee queen providing the progeny emerged on 15 May 2019. The colony infested with $V$. destructor was kept under natural conditions throughout the study. The average abundance calculated right before the implementation of the non-invasive analysis was 108.6 adult mites/frame. The last acaricide treatment of this colony was effectuated on 08 September 2018, after which other pesticides were not administered.

\subsection{Description of the examination setup}

In the course of the experiment, the colony was observed daily and the batches of the eggs laid simultaneously were analysed by CT (18 August 2019.). The broods were uniformly closed on the 9th day following egg-laying. After the brood coverage, a brood comb of $8 \times 10 \mathrm{~cm}$ of the workers was cut from the centre of the frame, which was subsequently assigned to $\mathrm{CT}$ examination at equal intervals, four times during the post-embryonic development: on the 14th, 16th, 18th, and 20th day from the onset of egg-laying. One hundred fifty pupae were assayed, from which 10 intact and 10 infested pre-imaginal specimens were randomly selected for comparison. The sensitivity of the CT-method was visually examined by detecting $V$. destructor in the brood's cells, which was tested by extracting unexamined brood's cells in 10 replications. This comparison method was always carried out by two persons. Volume and tissue density data of pupae were gathered by means of computed tomography, from which the change in physiological characteristics of the honey bee pupae could be concluded. Between each recording, the comb sample was placed back to its original position in the frame. At the end of the survey, these examined worker pupae were removed from their brood cells and the number of adult female mites per cell was determined by their distinct, darker cuticle and signs of wear; subsequently the host bees were weighed on a micro-scale (Sartorius A120S) with the accuracy of $1 \mathrm{mg}$. 


\subsection{Computed tomography-assisted imag- ing analysis}

The CT measurements were performed using a Siemens Somatom AS + CT scanner (Siemens Ltd., Erlangen, Germany). The following scanning parameters were used for data collection: $140 \mathrm{kV}, 200 \mathrm{mAs}$ and spiral data collection with pitch 0.7 , UHR (Ultra High Resolution) mode. Axial scans were reconstructed at every $0.1 \mathrm{~mm}$ increment with $0.6-\mathrm{mm}$ slice thickness and $60-\mathrm{mm}$ field of view using V80 u convolution kernel. The images were archived in DICOM (Digital Imaging and Communications in Medicine) format and each of the series was subsequently converted to NIFTI (Neuroimaging Informatics Technology Initiative) metafiles. The resolution of the meta-images was nearly isotropic: $0.117 \times 0.117 \times 0.1 \mathrm{~mm}^{3}$.

The first step during the implementation of the analysis was the separation and identification of the individuals. The pupae were segmented manually using the segment editor module of the 3D Slicer program (Fedorov et al. 2012). The average radiodensities and volumes of the pupae were calculated using the voxels belonging to the pupae. Subsequently, the coordinates of those pupae voxels were considered to be the coordinates of the surface points of the pupae. Based on these 3-D point clouds, the surfaces of individual seeds were reconstructed through triangularisation. The 3-D models of seeds were created for measuring the surface size and visualisation of the pupae, in order to test the volume, surface and tissue density [(Hounsfield Unit (HU) is a quantitative value for describing radiodensity. It is frequently used in CT scans, where its value is also termed CT number].

\subsection{Statistical analysis}

For Hounsfield Unit and the weight values of the examined honey bee pupae, the Shapiro-Wilk test was used. For the survey of the normal distribution of data $(P<0.05)$, the Ghasemi- and Zahediasl-type methods were employed. The effects of $V$. destructor (post-embryonic development and health condition were the independent variables) on the volume $\left(\mathrm{mm}^{3}\right)$, the surface $\left(\mathrm{mm}^{2}\right)$ and the tissue density (HU) of infested pupae (as dependent variables) and its interaction with preimaginal development were statistically analysed by two-way ANOVA. The impact of mite parasitism on the weight of honey bee pupae measured at the end of the survey was evaluated by one-way ANOVA via using the SPSS for Windows 11.5 software package. Mean values were separated by using the Tukey test, at $P \leq 0.05$.

\section{RESULTS}

\subsection{Sensitivity of CT for mite detection and infestation rate}

The detection rate of $V$. destructor present in the analysed comb by CT has continuously increased during the progress of post-embryonic development of honey bee pupae. The early developing stage of parasite can be seen in the lateral side of pre-imaginal honey bee pupae in Figure 1. The perception rates of the parasite in the four non-invasive recordings were the following: $1 \mathrm{st}$ recording, 43.33\%; 2nd, 76.66\%; 3rd, 90\%; 4th, $100 \%$.

The infestation in the experimental comb was $21.31 \%$ (Figure 2). Additionally, the average number of mites per one infested cell was 4.68 , which has been determined after the opening of cells at the end of the experiment.

\subsection{Volume, surface and tissue density data of pupae}

The Shapiro-Wilk normality test showed that our CT-measured data are of normal distribution, $P>0.05$. Uniform significant differences in the tissue density of pupae between intact and infested samples were revealed by statistical analysis.

The effect of post-embryonic development on the change in volume $\left(P=2.47 \times 10^{-19}\right)$, surface $\left(P=4.91 \times 10^{-18}\right)$ and tissue density $(P=1.73 \times$ 


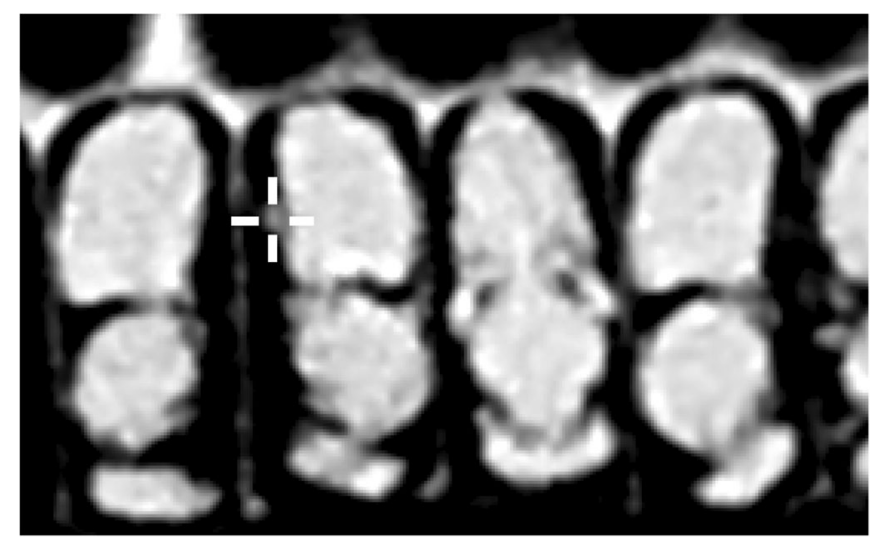

Figure 1. Axial CT recordings of honey bee pupae with feeding $V$. destructor (marked by white cross).

$10^{-8}$ ) data of pupae was confirmed by two-way ANOVA.

Volume reduction in pupae triggered by $V$. destructor could be detected in this

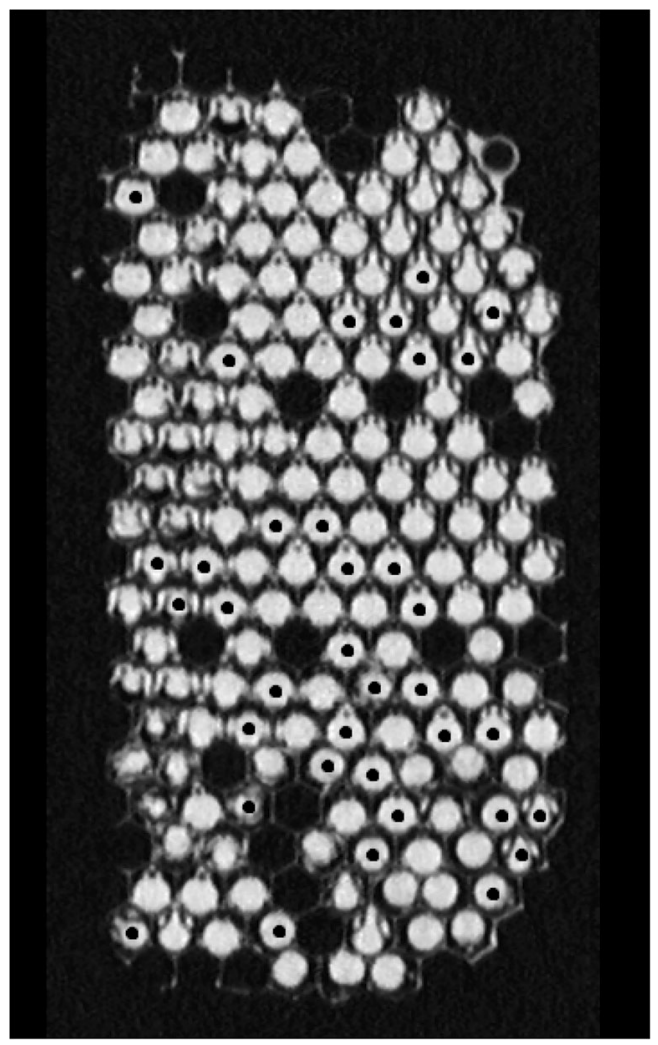

Figure 2. Experimental sample of honey bee comb with black spot marking of infested cells by $V$. destructor . experiment (Figure 3a, b, c, d, e, f, g, and h). The volumes of the parasite-infected pupae and intact pupae as well decreased in each observation record with the exception of the 2 nd recording. We showed a remarkable difference on the 1st recording as well (2.898 $\mathrm{mm}^{3}$ ), but the most spectacular difference $\left(3.435 \mathrm{~mm}^{3}\right)$ between the volumes of the infested samples and those of the intact ones was measured on the 3rd recording. Nonetheless, the effect of mite parasitism on volume decrease in bee pupae could not be proven statistically $(P=0.271)$ by two-way ANOVA. The combined effect of preimaginal development and parasitism on the volume change in the bee pupae showed a not statistically proven relationship $(P=0.692)$.

The surface of intact and infested samples within the same recording was examined in conjunction with the volume. The surface of the examined intact samples was $136.711 \pm$ $1.276 \mathrm{~mm}^{2}$ at the end of the examination. The surface loss in the infested pupae was $0.667 \mathrm{~mm}^{2}$ on average on the 4 th recording, but this decrease $(P=0.842)$ and the interaction with pre-imaginal development $(P=$ $0.085)$ were not statistically confirmed.

The pupae tissue densities expressed by Hounsfield Unit (HU) of intact and infested honey bees are shown in Figure $4 \mathrm{a}, \mathrm{b}, \mathrm{c}, \mathrm{d}$, $\mathrm{e}, \mathrm{f}, \mathrm{g}, \mathrm{h}$, and i. The samples infested by $V$. destructor have lower radiodensity values than those of the intact samples, which has 


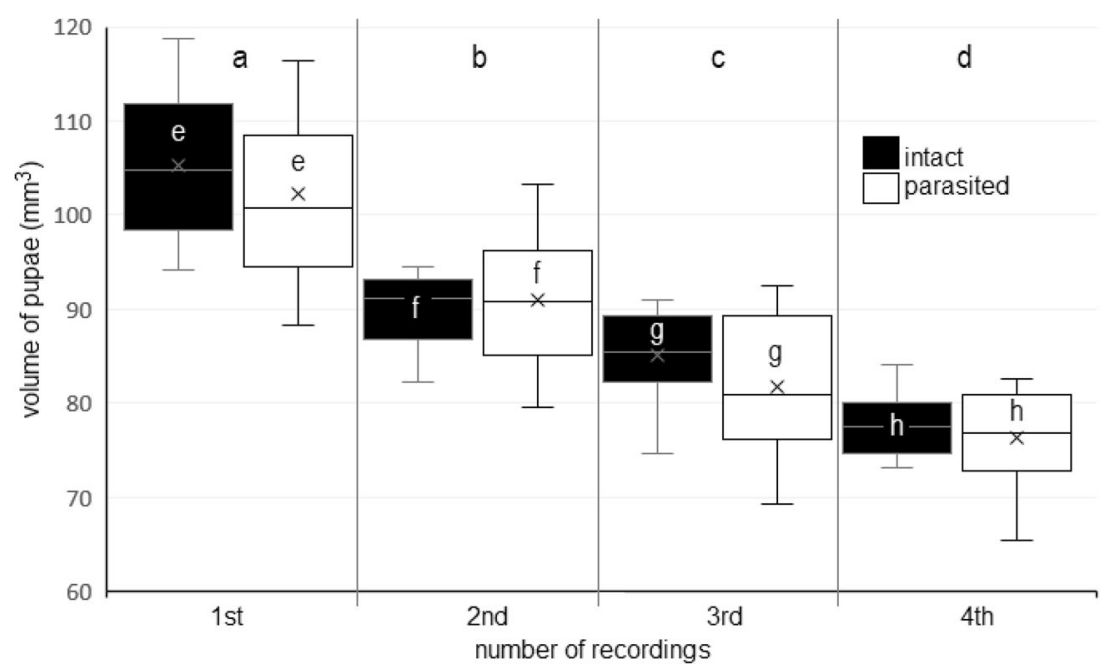

Figure 3. The volume $\left(\mathrm{mm}^{3}\right)$ changing of honey bee pupae during the examination as a function of $V$. destructor parasitism $(n=20)$. (a, b, c, d) Small letters indicate significant difference $(p \leq 0.05)$ between means of different recording times; $(\mathrm{e}, \mathrm{f}, \mathrm{g}, \mathrm{h})$ small letters indicate significant difference $(p \leq 0.05)$ between intact and parasite samples.

been confirmed by two-way analysis of variance $\left(P=8.64 \times 10^{-6}\right)$. The mean changing density of the infested pupae was $1.657 \mathrm{HU}$ $(1.481 \%)$. Eventually, the dense tissue formation has disappeared from the pupae of honey bee, which may be due to sucking by $V$. destructor. Nonetheless, the interaction of the parasitism and the development could not be statistically confirmed $(P=0.084)$.

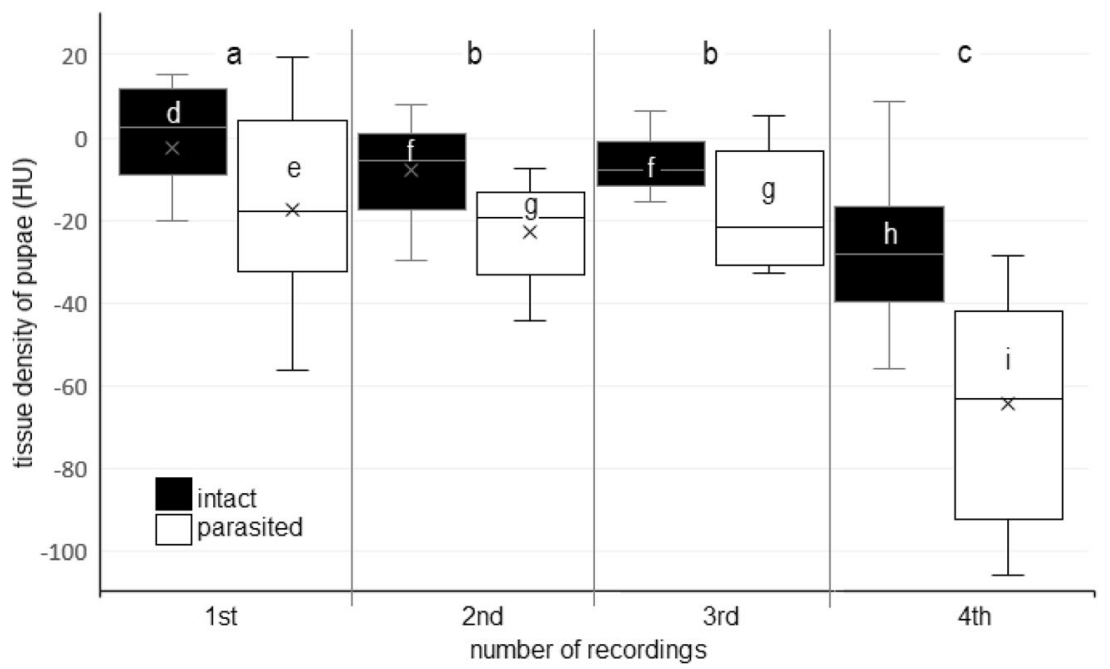

Figure 4. The tissue density (HU) changing of honey bee pupae during the examination as a function of $V$. destructor parasitism $(n=20)$. (a, b, c) Small letters indicate significant difference $(p \leq 0.05)$ between means of different recording times; ( $\mathrm{d}, \mathrm{e}, \mathrm{f}, \mathrm{g}, \mathrm{h}, \mathrm{i})$ small letters indicate significant difference $(p \leq 0.05)$ between intact and parasite samples. 


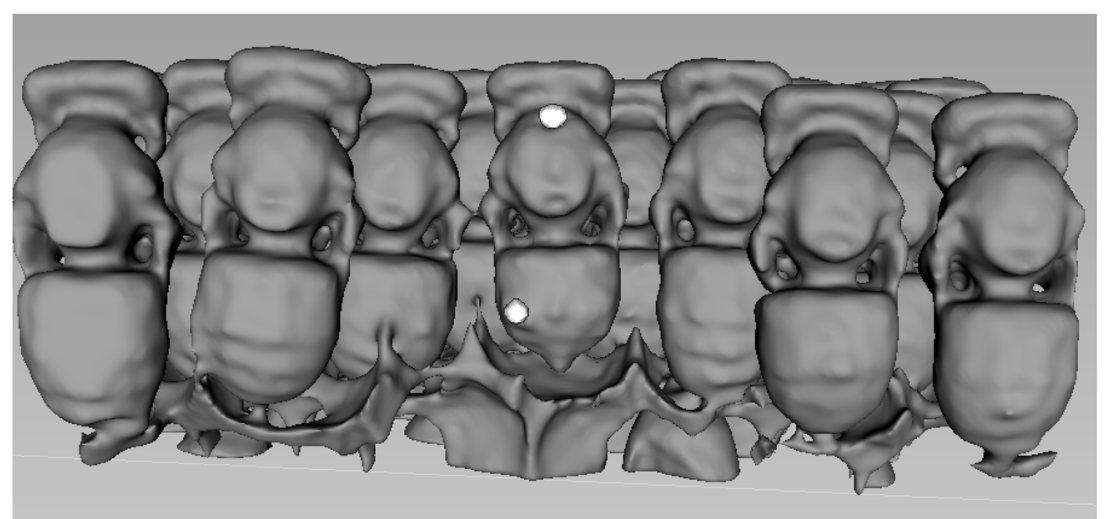

Figure 5. Computer-based three-dimensional reconstructions of honey bee pupae infested by $V$. destructor in the comb. V. destructor are marked by white spots.

\subsection{Weight of pupae}

The weight loss of honey bee pupae attacked by $V$. destructor (Figure 5) was evinced. The mean of calculated weight of the infested pupae was $105.2 \pm 0.001 \mathrm{mg}$, while the same developing stage (healthy stage) was $121.9 \pm 0.001 \mathrm{mg}$, which represents $16.6 \mathrm{mg}(13.665 \%)$ weight loss in the case of the damaged honey bee pupae. The effect of parasitism on the weight of this preimaginal stadium of honey bee was statistically demonstrable $\left(P=8.41 \times 10^{-7}\right)$ by one-way ANOVA.

\section{DISCUSSION}

It is claimed that computer tomography as a new, non-invasive method in apiary researches is suitable for the detection of $V$. destructor in comb cells. Naturally, the detection rate depends on the operator's aptitude, but generally, the later the scan, the easier it is to spot a mite in a cell. However, it proved most suitable in observations at more advanced developing stages of mite, at which the deutochrysalis has already exhibited the final body shape. At the deutochrysalis stage, the coloration starts on the periphery of the opisthosoma and shifts to a reddish-brown colour after the moult of the female (Rosenkranz et al. 2010). Further, the better detection of parasites by CT at late developmental stages can be partly explained by the hidden lifestyle of both the founder mite and the larvae at earlier developing stages. The nymphs are generally located on the 5th segment on the bee pupa and near the socalled faecal accumulation site at the bottom of the cell (Kanbar and Engels 2003).

The infestation rate of $V$. destructor reported in this study can be considered to be the average infestation rate on the basis of the relevant data, which substantially vary between $7 \%$ (De Guzman et al. 2007) and 30\% (Rosenkrantz et al. 2006). Besides, it cannot be excluded that the infestation rate can reach higher value in a comb as $V$. destructor might not infest cells in a uniform way within a comb (Facchini et al. 2019). The recorded number of parasite mites in one cell coincided with the normal progeny rate of $V$. destructor reported in previously published works. It is normal for a fertile mite to lay five eggs (one male and four females) in worker cells, which can be located close to each other (Martin 1995; Rosenkranz et al. 2010).

The anatomical features measured by $\mathrm{CT}$ in developing honey bee pupae were unequivocally influenced by parasitism. According to our CTassisted observation, the developing honey bee pupae have retained their volume and surface values (which can be partially explained by the normal post-embryonic development too), while the weight loss triggered by $V$. destructor was observable. These results are in line with the data presented previously in the relevant literature (Colin et al. 1999; van Engelsdorp et al. 2007; 
Facchini et al. 2019). Duay et al. (2003) have presented the first reliable data on individual drone weight loss, especially from the red-eyed pupal stage onwards. The resulting reduction in the weight of adult drones was related to the number of female mites (up to 20) that had invaded a brood cell.

The diminished radiodensity in animal tissues (e.g. fat) in infested pupae can be explained by the disappearance of high-density organic (e.g. proteins, carbohydrates) and inorganic (e.g. water) materials (Romvari et al. 1996; McEvoy et al. 2008). In this context, it is worth mentioning that water (as an essential component) can be found in the largest quantities in insect haemolymph (Shaw and Stobbart 1963).

Albeit direct tissue analysis was not carried out in this study, based on our results, it can be inferred that the content of haemolymph could be decreased primarily by $V$. destructor parasitism due to water being the densest and the highest proportion component of this insect tissue. The results of former experiments are confirmed by our findings. Ramsey et al. (2019) showed that this parasite does not only consume body fat but also damages host bees by haemolymph sucking, a phenomenon which could not be verified by our study. Varroa parasitism is associated with impaired development of immature bees, decreased lipid synthesis, reduced protein titers, desiccation, impaired metabolic function, inability to replace lost protein, precocious foraging, heightened winter mortality, impaired immune function, decreased longevity and reduced pesticide tolerance (Bowen-Walker and Gunn 2001; van Dooremalen et al. 2013).

In summary, our results can shed light on the consequences of the damage brought about by $V$. destructor during the pre-imaginal stages of honey bee development in a non-invasive way. Our reconnaissance study in the detailed biology of this important ectoparasite can play an important role in the understanding of some viral disorders transferred by mite (e.g. CCD) as well as the elaboration of strategies aimed at successful protection method against it. These novel data originating from $\mathrm{CT}$ imaging can contribute to the understanding of the complex phenomenon of colony collapse disorder.

\section{AUTHORS' CONTRIBUTIONS}

Sandor Keszthelyi and Tamas Donko conceived and designed the research project. Tamas Sipos provided the experimental bee colony. Tamas Donko and Tamas Sipos conducted the experiments. Adam Csoka and Tamas Sipos did the CT image post-processing and connected data analysis. All authors analysed the data. Sandor Keszthelyi wrote the manuscript. All authors read and approved the manuscript.

\section{FUNDING INFORMATION}

Open access funding provided by Kaposvár University. The work was supported by the GINOP2.2.1-15-2016-00021 and the EFOP-3.6.3VEKOP-16-2017-00008 projects. The project is co-financed by the European Union, the European Regional Development Fund and the European Social Fund.

\section{COMPLIANCE WITH ETHICAL STANDARDS}

Conflict of interest The authors declare that they have no potential conflict of interest in relation to the study presented in this paper.

\section{OPEN ACCESS}

This article is licensed under a Creative Commons Attribution 4.0 International License, which permits use, sharing, adaptation, distribution and reproduction in any medium or format, as long as you give appropriate credit to the original author(s) and the source, provide a link to the Creative Commons licence, and indicate if changes were made. The images or other third party material in this article are included in the article's Creative Commons licence, unless indicated otherwise in a credit line to the material. If material is not included in the article's Creative Commons licence and your intended use is not permitted by statutory regulation or exceeds the permitted use, you will need to obtain permission directly from the copyright holder. To view a copy of this licence, visit http://creativecommons. org/licenses/by/4.0/.

Analyse par tomographie assistée par ordinateur des effets destructeurs de Varroa destructor sur le développement préimaginal de l'abeille, Apis mellifera. 
tomographie par ordinateur / développement préimaginal / abeille domestique

Eine CT-Analyse der negativen Auswirkungen von Varroa destructor auf die on the preimaginal development of honey bee, Apis mellifera.

\section{Computertomograph / präimaginale Entwicklung / Honigbiene}

\section{REFERENCES}

Anderson, D.L., Trueman, J.W.H. (2000) Varroa jacobsoni (Acari: Varroidae) is more than one species. Exp. Appl. Acarol. 24 (3), 165-189

Anguiano-Baez, R., Guzman-Novoa, E., Hamiduzzaman, M.M., Espinosa-Montaño, L.G., Correa-Benítez, A. (2016) Varroa destructor (Mesostigmata: Varroidae) parasitism and climate differentially influence the prevalence, levels and overt infections of deformed wing virus in honey bees (Hymenoptera: Apidae). J. Insect Sci. 16 (1), 44.

Bowen-Walker, P.L., Gunn A. (2001) The effect of the ectoparasitic mite, Varroa destructor on adult worker honeybee (Apis mellifera) emergence weights, water, protein, carbohydrate, and lipid levels. Entomol. Exp. Appl. 101 : 207-217.

Colin, M.E., Fernandez, P.G., Ben Hamida, T. (1999) Varoosis, bee disease diagnosis. Opt. Méditerr. 25, 121-142.

De Jong, D., De Jong, P.H. (1983) Longevity of Africanized honeybees (Hymenoptera: Apidae) infested by Varroa jacobsoni (Parasitiformes: Varroidae). J. Econ. Entomol. 76 (4), 766-768.

De Jong, D., De Jong, P.H., Gonçalves, L. (1982) Weight loss and other damage to developing worker honeybees from infestation with Varroa jacobsoni . J. Apic. Res. 21 (3), 165-167.

Duay, P., De Jong, D., Engels, W. (2003) Weight loss in drone pupae (Apis mellifera) multiply infested by Varroa destructor mites. Apidologie 34 (1), 61-65.

Facchini, E., Nalon, L., Andreis, M.E., Di Giancamillo, M., Rizzi, R., Mortarino, M. (2019) Honeybee pupal length assessed by CT-scan technique: effects of Varroa infestation, developmental stage and spatial position within brood comb. Sci. Rep. 9, 10614

Fedorov, A., Beichel, R., Kalpathy-Cramer, J., Finet, J., Fillion-Robin, J.C., Pujol, S., Bauer, C., Jennings, D., Fennessy, F.M., Sonka, M., Buatti, J., Aylward, S.R., Miller, J.V., Pieper, S., Kikinis, R. (2012) 3D Slicer as an image computing platform for the quantitative imaging network. Magn. Reson. Imaging. 30, 1323-1341.
Genersch, E., Aubert, M. (2010) Emerging and reemerging viruses of the honey bee (Apis mellifera L.). Vet. Res. 41 (6), 54.

Guzman, L., Rinderer, T.E., Frake, A. (2007) Growth of Varroa destructor (Acari: Varroidae) populations in Russian honey bee (Hymenoptera: Apidae) colonies. Ann. Entomol. Soc. Am. 100 (2), 187-195.

Kanbar, G., Engels, W. (2003) Ultrastructure and bacterial infection of wounds in honey bee (Apis mellifera) pupae punctured by Varroa mites. Parasitol. Res. 90 (5), 349-354.

Martin, S.J. (1995) Ontogenesis of the mite Varroa jacobsoni Oud. In the drone brood of the honeybee Apis mellifera L. under natural conditions. Exp. Appl. Acarol. 19, 199-210.

McEvoy, F.J., Madsen, M.T., Strathe, A.B., Svalastoga. E. (2008) Hounsfield Unit dynamics of adipose tissue and non-adipose soft tissues in growing pigs. Res. Vet. Sci. 84, 300-304.

Ramsey, S.D., Ochoa, R., Bauchan, G., Gulbronson, C., Mowery, J.D., Cohen, A., Lima, D., Joklik, J., Cicero, J.M., Ellis, J.D., Hawthorne, D., van Engelsdorp D. (2019) Varroa destructor feeds primarily on honey bee fat body tissue and not hemolymph, Proc. Natl. Acad. Sci. 116 (5), 1792-1801.

Romvari, R., Milisits, G., Szendro, Z., Sorensen, P. (1996) Non-invasive method to study the body composition of rabbits by X-ray computerised tomography. World Rabbit Sci., 4 (4), 219-224.

Rosenkrantz, P., Fries, I., Imdorf, A. (2006) Survival of mite infested (Varroa destructor) honey bee (Apis mellifera ) colonies in Nordic climate. Apidologie, 37 (5), 564-570.

Rosenkranz, P., Aumeier P., Ziegelmann, B. (2010) Biology and control of Varroa destructor. J. Invertebr. Pathol. 103 (1), 96-119.

Sammataro, D., Gerson, U., Needham, G. (2000) Parasitic mites of honey bees: life history, implications and impact. Ann. Rev. Entomol. 45, 519-548.

Shaw, J., Stobbart, R.H. (1963) Osmotic and ionic regulation in insects. Adv. Ins. Physiol. 1, 315-319.

van Dooremalen C, Stam, E., Gerritsen, L., Cornelissen, B., van der Steen, J., van Langevelde, F., Blacquière, T. (2013) Interactive effect of reduced pollen availability and Varroa destructor infestation limits growth and protein content of young honey bees. J. Insect Physiol. 59 : 487-493.

van Engelsdorp, D., Underwood, R., Caron, D., Hayes, J. (2007) An estimate of managed colony losses in the winter of 2006-2007: a report commissioned by the apiary inspectors of America. Am. Bee J. 147, 599-603.

Yang, X., Cox-Foster, D.L. (2005) Impact of an ectoparasite on the immunity and pathology of an invertebrate: evidence for host immunosuppression and viral amplification, Proc. Natl. Acad. Sci. 102 (21), 7470-7475.

Publisher's note Springer Nature remains neutral with regard to jurisdictional claims in published maps and institutional affiliations. 